\title{
The Neurotic Paradox in Action
}

\author{
James F Welles* \\ P O Box 17, East Marion, New York, USA \\ *Corresponding author: James F Welles, P O Box 17, East Marion, New York, USA
}

\section{Opinion}

As a means to short-term adaptation/long-term demise, the human mind is a classic example of the "Neurotic Paradox" in action as it promotes behavioral patterns which are subject to immediate, short-term reinforcement although the long-term results will be decidedly negative[1]. A related drawback is that short-term errors may be hard to overcome in the long run[2] if the immediate decision sets one off on a bad behavioral pathway which becomes progressively more and more difficult to escape from later. Addictions to drugs or "Pleasure" would be commonplace examples of this basic physio/ psychological principle of learning and life[3]. As philosopher Honoré de Balzac noted, "Pleasure is like certain drugs, to continue to obtain the same result, one must double the dose, and death or brutalization is contained in the last one"[4].

If the human mind is adaptive in helping one fit into his immediate surroundings, it is maladaptive over the long run, as it inhibits innovations and constructive criticism of the social environment. Individuals adjust to the group, but the group loses its capacity to adjust to its surroundings as members sacrifice their individual integrity, insight and ideas and conform to prevailing mores for the rewards of social acceptance.

Of course, the bottom line, long-term net effect of the neurotic paradox is negative, but its universal presence cannot be understood without recognition of its role in helping people adapt to their immediate, short-term social situation. Thus, it becomes clear how there can be so much stupidity around although it is, in the long run, maladaptive. Survival within the system is promoted if one is so stupid as to accept the system's stupidities. Also, shortterm survival of the system (institution, group, etc.) is promoted through enhanced social cohesion. However, these immediate gains are countered by the long-term loss of induced inefficiency of information processing.

Our cultural life is really a very human trade off among these three dependent features:
1. Objective, rational, logical processing of information.

2. Psychological gratification and self-image of the individual and

3. Group cooperation[5] and social cohesion.

With the qualification of arbitrariness in mind, it should be noted that most people who find stupidity in others judge efficiency of processing information and usually do not even consider the emotional and social dimension of decisions affecting individual and institutional life. Accordingly, what might be regarded as stupidity may in fact be a healthy, short-term compromise with psychic satisfaction and group cohesion. Real stupidity comes when one factor (information processing, psychic comfort, or social cohesion) disrupts the others.

The Psychotic Paradox (Welles. 2020.), on the other hand, is a psycho/cultural mechanism of delayed gratification which blocks short-term, immediate presumed advantages for the sake of possible rewards to be gained later-as when a worker goes on strike, thus sacrificing the all but tangible reality of the next paycheck for the sake of a potentially bigger one in the future. Corporation founder Walter Chrysler personified this principle: He was always willing to accept a short-term risk for a long-term payoff. (Cochran. T. "Walter Percy Chrysler" Dictionary of American Bio. 1955.)

\section{References}

1. Mowrer 0 (1950) Learning Theory and Personality Dynamics. Deficit spending is a good example of the n-dox in government. Ronald Press; New York. Pp: 524.

2. Lorenz E (1972) Predictability. American Association of Science. Oxford University Press; New York.

3. Williams G, Nesse R (1991) The dawn of Darwinian medicine. The Quarterly Review of Biology 66(1): 1-22.

4. Balzac H (1834) The Girl with the Golden Eyes. Charpentier; Paris, France. 
5. Axelrod R (1984) The Evolution of Cooperation. 1984/2006. Penguin; London, England.

(c) This work is licensed under Creative

To Submit Your Article Click Here: Submit Article

DOI: $10.32474 / 0 J N B D .2020 .04 .000186$

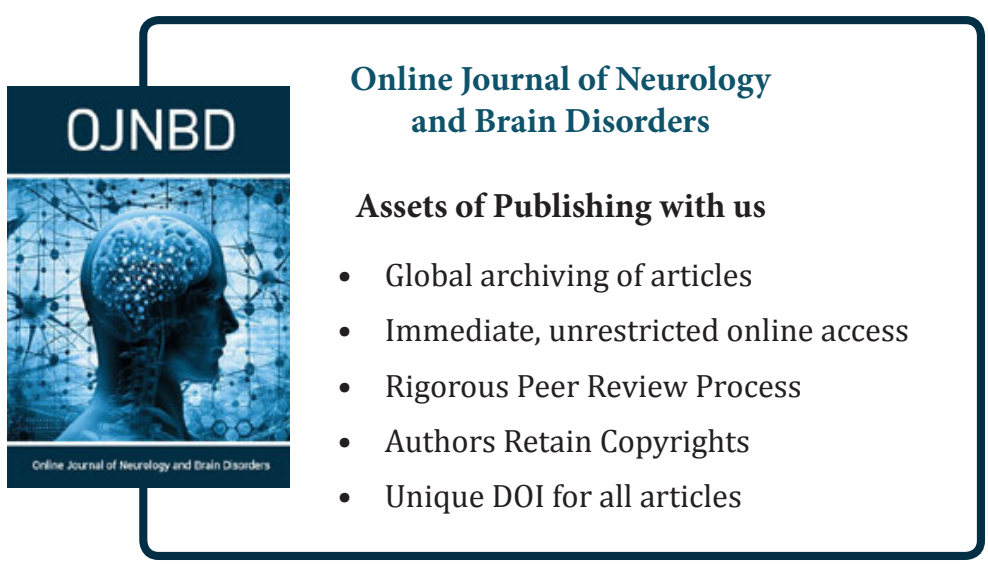

